Article

\title{
Application of Composite Pre-Polymerized Coagulants for the Treatment of High-Strength Industrial Wastewaters
}

\author{
Athanasia K. Tolkou and Anastasios I. Zouboulis *(D) \\ Laboratory of Chemical and Environmental Technology, Department of Chemistry, Aristotle University of \\ Thessaloniki, GR-54124 Thessaloniki, Greece; tolkatha@chem.auth.gr \\ * Correspondence: zoubouli@chem.auth.gr; Tel.: +30-2310-997794; Fax: +302310997730
}

Received: 27 March 2020; Accepted: 25 April 2020; Published: 28 April 2020

\begin{abstract}
The aim of this study was the investigation of alternative pre-polymerized coagulants for the treatment of high-strength industrial wastewaters, such as those created by tanneries, or by yeast production industries. The novel inorganic composite coagulant examined in this study (as well as variations of it) was denoted as PSiFAC $1.5-10-15$. The contribution of a typical polyelectrolyte to improve the effectiveness of the coagulation/flocculation $(\mathrm{C} / \mathrm{F})$ process was additionally studied, either by adding it separately (i.e., as a flocculant aid) or by co-polymerizing it within the structure of inorganic coagulant (denoted as PAPEFAC $1.5-10-15$ ). It was found that the PSiFAC $1.5: 10: 15$ coagulant, either with or without the addition of polyelectrolyte, can provide better efficiency for the C/F process than the conventional coagulants. For example, the addition of $80 \mathrm{mg} \mathrm{Al} / \mathrm{L}$ in yeast production wastewater samples resulted in a $56 \%$ reduction of COD, $40 \%$ of turbidity, and $43 \%$ of phosphates, regarding the pre-treated anaerobically wastewater samples and reduced by an extra $22 \%, 14 \%$, and $38 \%$ for the pre-treated anaerobically plus aerobically wastewater samples, respectively. The residual aluminum concentration in the treated wastewaters was found to be below the legislation limit of $200 \mu \mathrm{g} \mathrm{Al} / \mathrm{L}$. The characterization of coagulants showed the relatively higher $\mathrm{Al}_{13}$ content of $51 \%$

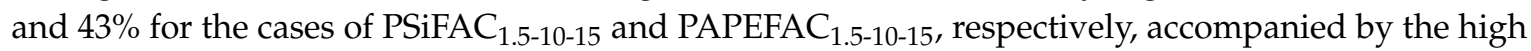
zeta-potential measurements ( 50.5 and $39.5 \mathrm{mV}$ ).
\end{abstract}

Keywords: composite pre-polymerized coagulants; high-strength industrial wastewaters; polyelectrolyte; poly-aluminum-ferric-silicate-chloride

\section{Introduction}

Domestic and industrial wastewaters can contain large concentrations of recalcitrant compounds, whereas their treatment by the application of biological processes in several cases was not found to be adequately effective, resulting in a treated effluent of rather low quality, e.g., causing severe eutrophication problems after disposal due to the remaining quite high nutrient concentrations (among others). For this case, particularly important is the presence of phosphorous (usually in the form of orthophosphates), which has to be efficiently removed (or recovered), especially from certain industrial wastewaters [1-3], noting that phosphorus can be removed from waters/wastewaters either biologically or (more effectively) by the addition of appropriate chemical agents [4].

In several wastewater treatment installations, the supplementary post-chemical treatment is commonly required to meet the respective strict effluent quality standards, especially regarding the discharge (i.e., the final permissible/legislative concentrations) of phosphorus. Membrane filtration is an attractive option to remove the chemically precipitated phosphorus, but this process can be impeded by the commonly encountered fouling of the membrane surface, mainly due to the usual 
presence of effluent organic matter (EfOM) [5]. Several studies have investigated the performance of MBR systems for treating high-strength wastewaters from food industries [6]. However, besides the satisfactory results, membrane fouling and the need for membrane cleaning could result in higher operational and maintenance costs when compared to conventionally applied treatment technologies.

Nowadays, industries face critical issues when achieving stringent water discharge requirements imposed by current legislation. High-strength industrial wastewaters are difficult to be classified, as there is no specific range to differentiate between low, medium, and high-strength wastewaters in industries. Wastewater "strength" can be different, depending on the industrial origin, and due to the different chemicals used during the main production process, i.e., food or chemical industries. Basically, a wastewater can be considered high strength when the major control parameters of this wastewater are in rather high concentrations such as of COD (Chemical Oxygen Demand), ammonia, suspended solids, or heavy metals, resulting sometimes in shock loadings. Wastewaters from the food industries mostly contain highly biodegradable organics in addition to increased nutrients (nitrogen and phosphorus) content [7-9]. Tannery is among the oldest industries in the world. It is typically characterized as highly polluted wastewater, containing a rather wide variety of high-strength toxic residues [10]. It is recognized as a serious environmental threat due to the high content of chemicals, increasing the values of major control parameters and including salinity, conductivity, chemical oxygen demand (COD), biological oxygen demand (BOD), inorganic matter, suspended solids (SS), total dissolved solids (TDS), heavy metals, etc.

The application of appropriate physicochemical pre-treatment to industrial wastewaters can also significantly improve the treated water quality, enhancing simultaneously the biodegradability of wastewater due to the removal of several recalcitrant compounds which can also cause treatment problems, etc. [11]. Chemical coagulation is usually employed to remove the suspended colloidal particles (i.e., within the $0.1-1 \mu \mathrm{m}$ size range) which cannot easily settle down and effectively separate on stillness conditions and cannot be easily removed by the application of other conventionally applied physical separation processes such as gravity settling, filtration, etc. [12,13]. The chemical coagulation/flocculation (C/F) process is considered an effective and commonly used physicochemical treatment option for several waters or wastewaters. It involves the addition of certain chemicals (coagulant agents), such as alum or ferric salts, aiming to cause interactions between the colloids and the hydrolyzed $\mathrm{Al}^{3+}$ or $\mathrm{Fe}^{3+}$ cations and to form neutral or slightly positively charged micro-flocs. Recently, Swain et al. (2020) [8] studied the combined chemical- and electro-coagulation process, used for the treatment of high-strength brewery wastewater, demonstrating the advantages of these treatment applications in terms of cost and high nutrient removal effectiveness. In addition, the coagulation-flocculation process has received greater attention, as it has been proven to be effective for the removal of various contaminants which may include toxic organic matter, heavy metals, viruses, etc. Due to the fact of its high-efficiency for the removal of contaminants, this process has been extensively applied (among other applications) for the treatment of leather industrial wastewater [14], palm oil mill effluent [15,16], food and beverage wastewater [8,9], textile wastewater [17], yeast wastewater [18], industrial wastewaters, etc. Traditionally, common inorganic metal salts, such as ferric chloride or aluminum sulfate, are widely used for industrial wastewater treatment. However, the use of inorganic coagulants has nowadays been reduced due to the fact of its rather narrow values of control parameters and lower efficiency when applied in smaller dosages [19]. Instead, several natural or synthetic polymeric coagulants or flocculants are preferable for the respective treatment processes.

Inorganic polymeric flocculants (IPFs), or pre-polymerized coagulants, such as poly-aluminum chloride $(\mathrm{PACl})$, represent a relatively new category of coagulant agents which were developed in order to increase the efficiency of the convenient coagulation/flocculation $(\mathrm{C} / \mathrm{F})$ process; however, there is still a need for the further improvement of their properties [20,21]. More recently, composite polymeric aluminum products, such as PASiC (aluminum-silicate polymer composite) [22,23] and polyferric silicate sulfate (PFSiS) [24], have been also examined in laboratory experiments as well as in full-scale applications. Several researchers (e.g., [25-28]) have studied the simultaneous addition of 
$\mathrm{Al}$ (III), Fe (III), and poly-silicic acid solution (pSi), whereas the coagulation efficiency of produced composite poly-aluminum-ferric-silicate-chloride is mainly affected by the $\mathrm{Al} / \mathrm{Fe} / \mathrm{Si}$ ratio and the respective preparation (i.e., inorganic polymerization) techniques.

Additionally, synthetic organic polyelectrolytes have already been utilized to enhance the $\mathrm{C} / \mathrm{F}$ process for water or wastewater treatment applications for more than four decades already. Due to the fact of their wide usage, they are considered also as alternative additives in the pre-polymerized coagulants for the production of new, modified composite coagulation reagents [24]. In previous studies, the use of pre-polymerized coagulants, based on iron or aluminum, was examined and found quite efficient for several water or wastewater applications, regarding, for example, the removal of turbidity [29,30], arsenic [31], fluoride [32], and the reduction of membrane fouling in MBR systems [33], producing also very low residual metal concentrations; this is also the case of PSiFAC product which is an aluminum-based pre-polymerized coagulant.

The aim of this study was the improvement of the effectiveness of $C / F$ process, using the composite poly-aluminum-ferric-silicate-chloride coagulants and a common anionic polyelectrolyte (Magnafloc-LT 25) as the flocculant aid for the treatment of certain high-strength industrial wastewater samples. Furthermore, the combination of coagulant and polyelectrolyte in one reagent was also examined for comparison reasons in order to increase further their flocculation efficiency by replacing the inorganic poly-silicate additive with the organic polyelectrolyte in their structure. To the best of our knowledge, there are no published data regarding the use of composite pre-polymerized coagulants, considering the treatment of high-strength wastewaters, and this study is an alternative and possibly promising approach for the effective processing of such kind of wastes [29-33].

The specific properties of novel coagulants were investigated by examining the aluminum species distribution, employing the ferron technique. The structure and the morphology of composite coagulants were studied in detail by the application of FTIR, XRD, and SEM techniques and by z-potential measurements. To the best of our knowledge, these coagulants have never been applied for the treatment of high-strength industrial wastewaters, while the use of PAPEFAC (i.e., coagulant and polyelectrolyte co-polymerized and producing a new composite reagent) is reported for the first time in the literature.

\section{Materials and Methods}

\subsection{Laboratory Procedure for the Preparation of Novel Composite Coagulants}

Composite poly-aluminum-ferric-silicate-chloride (PSiFAC) coagulants were produced at room temperature $\left(22^{\circ} \mathrm{C}\right)$, according to the procedure proposed by Tolkou et al. (2015) [30] under various experimental conditions and by applying different mixing orders of the used chemicals. All chemical reagents were of analytical pure chemical grade. The used initial solutions were: $0.5 \mathrm{M} \mathrm{AlCl}_{3} \cdot 6 \mathrm{H}_{2} \mathrm{O}$ (Merck), $0.5 \mathrm{M} \mathrm{FeCl}_{3} \cdot 6 \mathrm{H}_{2} \mathrm{O}$ (Merck), $0.5 \mathrm{M} \mathrm{NaOH}$ (Merck)-as the added base-and the prepared poly-silicic acid solution (pSi), according to Tzoupanos et al. (2009) [34]. The most effective coagulants and molar ratios obtained during preliminary experiments [30], such as $\mathrm{PSiFAC}_{1.5-10-15}$, were further examined in this study.

A solution of poly-acrylamide co-polymer (Magnafloc LT-25, Ciba SC LTD, commercially available), as a commonly used anionic polyelectrolyte (APE), was prepared $(0.01 \% w / v)$ and used both as a separate flocculant aid (with $[\mathrm{Al}] /[\mathrm{APE}]=10$, molar ratios) as well as the organic additive for the synthesis of new composite (inorganic-organic) coagulants (PAPEFAC). This specific polyelectrolyte is already widely applied as a flocculant aid in several water or wastewater treatment installations $[35,36]$. Table 1 presents the preparation conditions of all prepared and examined coagulants in this study. 
Table 1. Preparation conditions for the laboratory-prepared pre-polymerized coagulant agents, examined in this study.

\begin{tabular}{|c|c|c|}
\hline Coagulant Type & Molar Ratios & Procedure \\
\hline $\begin{array}{c}\text { PSiFAC }_{1.5-10-15} \\
\text { (poly-aluminum-ferric-silicate-chloride) }\end{array}$ & $\begin{array}{c}{[\mathrm{OH}] /[\mathrm{Al}]: 1.5} \\
{[\mathrm{Al}] /[\mathrm{Fe}]: 10} \\
{[\mathrm{Al}+\mathrm{Fe}] /[\mathrm{Si}]: 15}\end{array}$ & $\begin{array}{l}2 \mathrm{~mL} \text { of } 0.5 \mathrm{M} \mathrm{FeCl}_{3} \text { solution were added to } 20 \mathrm{~mL} \text { of } 0.5 \mathrm{AlCl}_{3} \text { solution under vigorous } \\
\text { stirring }(0.3 \mathrm{~mL} / \mathrm{min}, 20 \mathrm{rpm}) \text {. Then, } 1.92 \mathrm{~mL} \text { of pSi solution were added to the resulted } \\
\text { FpA solution and, subsequently, } 30 \mathrm{~mL} \text { of base solution were added slowly under } \\
\text { magnetic stirring }(0.1 \mathrm{~mL} / \mathrm{min}, 70 \mathrm{rpm}) \text { in the mixture [30] at } \mathrm{T}=30^{\circ} \mathrm{C} \text {. The composite } \\
\text { pre-polymerized material was left under stirring to mature for approximately } 1 \mathrm{~h} \text { and } \\
\text { then diluted with water to a final concentration of } 0.1 \mathrm{M} \text { relative to } \mathrm{Al} \text {. }\end{array}$ \\
\hline $\begin{array}{c}\text { PAPEFAC }_{1.5-10-15} \\
\text { (poly-aluminum-ferric-silicate-chloride) }\end{array}$ & $\begin{array}{c}{[\mathrm{OH}] /[\mathrm{Al}]: 1.5} \\
{[\mathrm{Al}] /[\mathrm{Fe}]: 10} \\
{[\mathrm{Al}+\mathrm{Fe}] /[\mathrm{APE}]: 15}\end{array}$ & $\begin{array}{l}2 \mathrm{~mL} \text { of } 0.5 \mathrm{M} \mathrm{FeCl}_{3} \text { solution were added to } 20 \mathrm{~mL} \text { of } 0.5 \mathrm{AlCl}_{3} \text { solution under vigorous } \\
\text { stirring }(0.3 \mathrm{~mL} / \mathrm{min}, 20 \mathrm{rpm}) \text {. Then, } 0.54 \mathrm{~mL} \text { of } \mathrm{APE} \text { solution were added to the resulted } \\
\text { FpA solution and, subsequently, } 30 \mathrm{~mL} \text { of base solution were added slowly under } \\
\text { magnetic stirring }(0.1 \mathrm{~mL} / \mathrm{min}, 70 \mathrm{rpm}) \text { in the mixture at } \mathrm{T}=30^{\circ} \mathrm{C} \text {. The composite } \\
\text { pre-polymerized material was left under stirring to mature for about } 1 \mathrm{~h} \text { and then diluted } \\
\text { with water to a final concentration of } 0.1 \mathrm{M} \text { relative to } \mathrm{Al} \text {. }\end{array}$ \\
\hline $\begin{array}{c}\text { PAFSiC }_{1.5-15-10} \\
\text { (poly-aluminum-ferric-silicate-chloride) }\end{array}$ & $\begin{array}{c}{[\mathrm{OH}] /[\mathrm{Al}]: 1.5} \\
{[\mathrm{Fe}] /[\mathrm{Si}]: 15} \\
{[\mathrm{Al}] /[\mathrm{Si}+\mathrm{Fe}]: 10}\end{array}$ & $\begin{array}{l}1.31 \mathrm{~mL} \text { of } \mathrm{pSi} \text { solution was added to } 15 \mathrm{~mL} \text { of } 0.5 \mathrm{M} \mathrm{FeCl}_{3} \text {, under vigorous stirring } \\
(0.3 \mathrm{~mL} / \mathrm{min}, 20 \mathrm{rpm}) \text {. Then, the resulted } \mathrm{FpSi} \text { solution was added to } 20 \mathrm{~mL} \text { of } 0.5 \mathrm{M} \\
\mathrm{AlCl}_{3} \text { solution and, subsequently, } 30 \mathrm{~mL} \text { of base solution were added slowly, under } \\
\text { magnetic stirring }(20 \mathrm{rpm})(0.1 \mathrm{~mL} / \mathrm{min}, 70 \mathrm{rpm}) \text { in the mixture at } \mathrm{T}=30^{\circ} \mathrm{C} \text {. The } \\
\text { composite pre-polymerized material was left under stirring to mature for about } 1 \mathrm{~h} \text { and } \\
\text { then diluted with water to a final concentration of } 0.1 \mathrm{M} \text { relative to } \mathrm{Al} \text {. }\end{array}$ \\
\hline $\begin{array}{c}\text { PFASiC }_{1.5-15-10} \\
\text { (poly-aluminum-ferric-silicate-chloride) }\end{array}$ & $\begin{array}{c}{[\mathrm{OH}] /[\mathrm{Al}]: 1.5} \\
{[\mathrm{Al}] /[\mathrm{Si}]: 15} \\
{[\mathrm{Al}+\mathrm{Si}] /[\mathrm{Fe}]: 10}\end{array}$ & $\begin{array}{l}1.75 \mathrm{~mL} \text { of } \mathrm{pSi} \text { solution was added to } 20 \mathrm{~mL} \text { of } 0.5 \mathrm{M} \mathrm{AlCl}_{3} \text { solution, under vigorous } \\
\text { stirring }(0.3 \mathrm{~mL} / \mathrm{min}, 20 \mathrm{rpm}) \text {. Then, } 2.13 \mathrm{~mL} \text { of } \mathrm{FeCl}_{3} \text { solution were added to the resulted } \\
\text { ApSi solution, } 30 \mathrm{~mL} \text { of base solution were added slowly under magnetic stirring } \\
(0.1 \mathrm{~mL} / \mathrm{min}, 70 \mathrm{rpm}) \text { in the mixture at } \mathrm{T}=30{ }^{\circ} \mathrm{C} \text {. The composite pre-polymerized } \\
\text { material was left under stirring to mature for about } 1 \mathrm{~h} \text { and then diluted with water to a } \\
\text { final concentration of } 0.1 \mathrm{M} \text { relative to } \mathrm{Al} \text {. }\end{array}$ \\
\hline $\begin{array}{c}\text { PASiC }_{1.5-15} \\
\text { (polyaluminum-silicate-chloride) }\end{array}$ & $\begin{array}{l}{[\mathrm{OH}] /[\mathrm{Al}]: 1.5} \\
{[\mathrm{Al}] /[\mathrm{Si}]: 15} \\
{[\mathrm{Al}+\mathrm{Si}] /[\mathrm{Fe}]: 0}\end{array}$ & $\begin{array}{l}1.75 \mathrm{~mL} \text { of } \mathrm{pSi} \text { solution was added to } 20 \mathrm{~mL} \text { of } 0.5 \mathrm{M} \mathrm{AlCl}_{3} \text { solution, under vigorous } \\
\text { stirring }(0.3 \mathrm{~mL} / \mathrm{min}, 20 \mathrm{rpm}) \text {. Then, } 30 \mathrm{~mL} \text { of base solution were added slowly under } \\
\text { magnetic stirring }(0.1 \mathrm{~mL} / \mathrm{min}, 70 \mathrm{rpm}) \text { in the mixture at } \mathrm{T}=30{ }^{\circ} \mathrm{C}[34] \text {. The composite } \\
\text { pre-polymerized material was left under stirring to mature for about } 1 \mathrm{~h} \text { and then diluted } \\
\text { with water to a final concentration of } 0.1 \mathrm{M} \text { relative to } \mathrm{Al} \text {. }\end{array}$ \\
\hline $\begin{array}{c}\mathrm{PACl}_{1.5(\mathrm{lab})} \\
\text { (polyaluminum-chloride) }\end{array}$ & {$[\mathrm{OH}] /[\mathrm{Al}]: 1.5$} & $\begin{array}{l}30 \mathrm{~mL} \text { of base solution were added slowly under magnetic stirring }(0.1 \mathrm{~mL} / \mathrm{min}, 70 \mathrm{rpm}) \\
\text { to } 20 \mathrm{~mL} \text { of } 0.5 \mathrm{M} \mathrm{AlCl}_{3} \text { solution, at } \mathrm{T}=30^{\circ} \mathrm{C} \text {. The composite pre-polymerized material } \\
\text { was left under stirring to mature for about } 1 \mathrm{~h} \text { and then diluted with water to a final } \\
\text { concentration of } 0.1 \mathrm{M} \text { relative to Al. }\end{array}$ \\
\hline
\end{tabular}




\subsection{Coagulation Experiments Performed by Jar-Tests}

The experimental procedure was conducted using a jar-test apparatus (Aqualytic) equipped with six paddles, employing $1 \mathrm{~L}$ glass beakers. Under rapid stirring of $200 \mathrm{rpm}$, a predetermined amount of coagulants was dosed. After $3 \mathrm{~min}$, the speed was changed to a slow stirring speed of $40 \mathrm{rpm}$ for $30 \mathrm{~min}$; after quiescent settling of $45 \mathrm{~min}$, samples were collected from $5 \mathrm{~cm}$ below the surface. Three types of industrial high-strength wastewater samples were examined: (1) a tannery wastewater; (2) a yeast manufacturing wastewater, subjected to preliminary anaerobic treatment; (3) a (similar) yeast manufacturing wastewater which was also subjected to aerobic treatment (besides anaerobic). The major parameters of the examined samples are presented in Table 2.

Table 2. Major physico-chemical parameters of examined wastewater samples.

\begin{tabular}{cccc}
\hline $\begin{array}{c}\text { Type of Wastewater } \\
\text { Samples to be Treated }\end{array}$ & Turbidity (NTU) & $\begin{array}{c}\text { COD } \\
\text { (Chemical Oxygen Demand) } \\
\text { (mg/L) }\end{array}$ & Phosphates (mg/L) \\
\hline Tannery wastewater & 668 & 6800 & 1.76 \\
\hline $\begin{array}{c}\text { Yeast wastewater (after } \\
\text { anaerobic treatment) }\end{array}$ & 418 & 11,455 & 3.49 \\
\hline $\begin{array}{c}\text { Yeast wastewater (the } \\
\text { previous, but after the } \\
\begin{array}{c}\text { additional post-aerobic } \\
\text { treatment as well) }\end{array}\end{array}$ & 143 & 4590 & 2.40 \\
\hline
\end{tabular}

After the C/F treatment, samples were collected from the supernatant of each beaker and were analyzed for the determination of major pollution parameters, i.e, (a) turbidity (NTU), by using a HACH RATIO/XR Turbidimeter; (b) COD (mg/L) spectrophotometrically after the appropriate oxidation pre-treatment by using the Lange spectrophotometer; and (c) phosphates $(\mathrm{mg} / \mathrm{L})$ by the ascorbic acid method [37].

\subsection{Characterization Methods}

\subsubsection{Physico-Chemical Properties}

All prepared composite coagulants were characterized by measuring: (a) the $\mathrm{pH}$ value using a Metrohm Herisau pH-Meter; (b) the turbidity using a Hach ratio/XR Turbidity-meter; and (c) the conductivity using a Crison CM 35 conductivity meter.

\subsubsection{Aluminum Species Distribution}

The distribution of aluminum species was determined with the application of Al-ferron timed spectrophotometric method which was based on the different reaction time of aluminum species with ferron reagent (8-hydroxy-7-iodoquinoline-5-sulphonic acid) to form water soluble complexes. These complexes can absorb light (maximum at $370 \mathrm{~nm}$ ); hence, the kinetic absorbance measurements at this wavelength may allow the calculation of three different (major) aluminum species (i.e., $\mathrm{Al}_{\mathrm{a}}$-monomers, $\mathrm{Al}_{\mathrm{b}}-\mathrm{Al}_{13}$ and $\left.\mathrm{Al}_{\mathrm{c}}-\mathrm{Al}(\mathrm{OH})_{3}\right)$; a Hitachi $\mathrm{UV} /$ vis spectrophotometer was used for this purpose.

\subsubsection{Scanning Electron Microscopy (SEM)}

Small portions of coagulant powders were obtained after drying in an oven $\left(\sim 40{ }^{\circ} \mathrm{C}\right)$ and used to observe the morphology of respective products, by employing a ZEISS EVO 50 scanning microscope. 


\subsubsection{Fourier-Transform-Infrared Spectroscopy (FTIR)}

The FTIR spectra of prepared composite products were recorded in the range of $4000-400 \mathrm{~cm}^{-1}$ using a Nicolet 380 FTIR Spectrometer-Thermo Scientific spectrophotometer to allow the observation of surface species and the possible polymeric interactions among the components.

\subsubsection{X-ray Diffraction Spectroscopy (XRD)}

X-ray diffraction spectroscopy (XRD) is an important tool for the identification of crystalline compounds, and it was applied to identify the possibly formed crystalline phases which are likely to be present in the prepared coagulants (such as $\left.\mathrm{Al}_{13}\right)$. The Malvern Panalytical Xpert instrument $(\mathrm{Cu}-\mathrm{K}$ radiation) was used, and the solid samples were analyzed in the range of $5-80^{\circ} 2 \theta$ with a scan rate of $1 \%$ min.

\subsubsection{Zeta-Potential and Particle Size Measurements}

The zeta-potential measurements were conducted with the ZETASIZER Nano-ZS (Malvern). For each (adjusted) $\mathrm{pH}$ value, three measurements of zeta-potential and the respective particle sizes were measured. The temperature was set at $20^{\circ} \mathrm{C}$. The particle sizes' distribution produced by each coagulant sample was calculated by assuming that their refractive index was equal to the refractive index of aluminum silicate. Dynamic light scattering (DLS) was used to measure the particle sizes of coagulants under different experimental conditions. This technique measures the diffusion of particles, moving under Brownian motion and converts this measurement to particle size and size distribution using the Stokes-Einstein relationship. Non-invasive back scatter technology (NIBS) was incorporated to give the highest sensitivity, simultaneously, with the highest size and concentrations range. The $\mathrm{pH}$ adjustments were conducted by using the MPT-2 Multi-Purpose Titrator (Malvern). The titration was necessary in order to scan (and maintain) the desirable $\mathrm{pH}$ range.

The z-potential measurements were performed by inserting a certain quantity of coagulant in deionized water and the instrument firstly is setting the $\mathrm{pH}$ value and then does the measurement. Then, the instrument sets a different $\mathrm{pH}$ value and measures again. It was not possible to insert actual wastewaters after the treatment in this instrument because all pipes, filters, etc., may be clogged and there would be several problems with the repeatability of measurements.

Furthermore, since the measurements were taking place using aqueous solutions of the examined coagulants, the obtained values were considered to be quite similar with the respective values expected if industrial wastewaters coagulation experiments were used for the specifically set (final) $\mathrm{pH}$ values.

\subsection{Residual Aluminum Concentration}

The residual aluminum concentration was determined by the Eriochrome cyanine $\mathrm{R}$ standard method [37]; dissolved aluminum ions react with Eriochrome cyanine $\mathrm{R}$ dye at $\mathrm{pH}$ 6, resulting in a colored compound with maximum absorbance at $535 \mathrm{~nm}$. The detection limit of this method (MDL) was $6 \mu \mathrm{g} / \mathrm{L}$.

\section{Results and Discussion}

\subsection{Major Physico-Chemical Properties of Prepared Coagulation Agents}

Table 3 displays the major physicochemical properties of laboratory prepared composite coagulants. It can be observed that the addition of poly-silicic acid (pSi) in the Al-Fe solution (denoted as FpA), when performed to induce the formation of composite coagulants, resulted in the increase of turbidity in comparison with the addition of anionic polyelectrolyte (APE) in the same FpA solution, i.e., the PSiFAC $_{1.5-10-15}$ and PAPEFAC $1.5-10-15$ products had 211 and 137 NTU values, respectively. 
Table 3. Major physicochemical properties of laboratory-prepared composite coagulants.

\begin{tabular}{ccccccc}
\hline \multirow{2}{*}{ Coagulant Type } & $\mathbf{p H}$ & \multirow{2}{*}{$\begin{array}{c}\text { Turbidity } \\
\text { (NTU) }\end{array}$} & $\begin{array}{c}\text { Conductivity } \\
(\mathbf{m S} / \mathbf{c m})\end{array}$ & \multicolumn{3}{c}{ Aluminum Species Distribution Al (\%) } \\
\cline { 5 - 7 } & & & & $\mathbf{A l}_{\mathbf{a}}$ & $\mathbf{A l}_{\mathbf{b}}$ & $\mathbf{A l}_{\mathbf{c}}$ \\
\hline PAFSiC $_{1.5-15-10}$ & 3.9 & 117.0 & 24.0 & 68 & 22 & 10 \\
\hline PFASiC $_{1.5-15-10}$ & 3.9 & 256.0 & 24.4 & 74 & 21 & 5 \\
\hline PSiFAC $_{1.5-10-15}$ & 3.5 & 211.0 & 23.7 & 44 & 51 & 5 \\
\hline PAPEFAC $_{1.5-10-15}$ & 3.6 & 137.0 & 27.0 & 51 & 43 & 6 \\
\hline PACl $_{1.5(\text { lab })}$ & 3.8 & 2.1 & 21.4 & 47 & 39 & 14 \\
\hline
\end{tabular}

The mixing order of $\mathrm{Al} / \mathrm{Fe} / \mathrm{Si}$ components was also found to affect significantly the turbidity of products. Specifically, when $\mathrm{Al}$ was firstly added to $\mathrm{pSi}$, i.e., to prepare the $\mathrm{PSiFAC}_{1.5-10-15}$ product, the turbidity value was quite high (211 NTU), most likely due to the interaction between the chemical forms of Al and Si, as Duan and Gregory (1998) [38] suggested, arguing that in aqueous solutions, silicic acid can interact with the chemical forms of $\mathrm{Al}$ to form hydroxy-alumino-silicate complexes (HAS). Unlike the aforementioned case (i.e., regarding the product PSiFAC $1.5-10-15$ ), when the mixing sequence was different (i.e., $(\mathrm{Fe}+\mathrm{pSi})+\mathrm{Al})$, as in the $\mathrm{PAFSiC}_{1.5-15-10}$ product, the respective turbidity was found to be much lower (117 NTU), possibly because Si is firstly bound with Fe.

From the results presented in Table 3, it appears that the mixing order of components may also affect the percentage of medium-sized forms of polymerized aluminum (i.e., $\mathrm{Al}_{\mathrm{b}}$ ), and the (desired) $\mathrm{Al}_{13}$ content (specifically in the case of PSiFAC $1.5-10-15$ ) was found to increase (i.e., $\mathrm{Al}_{13} 51 \%$ ) as compared with the corresponding value of $\mathrm{Al}_{13}(29 \%-32 \%)$ found in the laboratory-prepared $\mathrm{PACl}_{\text {lab }}$ product (also confirmed by Yan et al. (2008) [39]); therefore, an improved product was obtained.

Finally, by studying the effect of polyelectrolyte addition on the composition of obtained product, it was found that the degree of polymerization and the content $(\%)$ of $\mathrm{Al}_{\mathrm{b}}$, when using an anionic polyelectrolyte instead of poly-silicic acid, presented relatively higher values. Particularly, the two products, PAPEFAC $1.5-10-15$ and PSiFAC $1.5-10-15$, based on the values in Table 3, exhibited the (desirable) highest percentage of medium-sized polymerized forms of aluminum $\left(\mathrm{Al}_{\mathrm{b}}\right)$, favoring the formation of higher $\mathrm{Al}_{13}$ content.

\subsection{Characterization of New Polymerized Composite Coagulant Agents}

\subsubsection{Structure Analysis}

The possible chemical bonds, being present in the produced composite coagulants, were examined. Figure 1 illustrates the FTIR spectra of selected products, regarding the different mixing order of $\mathrm{Al} / \mathrm{Fe} / \mathrm{Si}$ components. All these spectra were found to exhibit two characteristic bonds at different wavelengths (i.e., at $3500-3300 \mathrm{~cm}^{-1}$ ) attributed to the stretching vibration of $-\mathrm{OH}$ and at $1641-1638 \mathrm{~cm}^{-1}$, which can be attributed to the bending vibration of water absorbed, polymerized, and crystallized in the coagulant structure. The spectra of composite coagulants, corresponding to the stretching vibration of

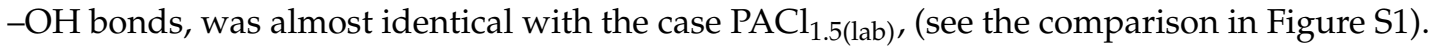

As shown in Figure 1, the band at $1038 \mathrm{~cm}^{-1}$ was assigned to the asymmetric $\mathrm{Si}-\mathrm{O}$ stretching vibrations of $\mathrm{Si}-\mathrm{O}-\mathrm{Si}$ bonds [40] which is indicative of the high polymerization degree of silica. In addition, there were two characteristic peaks: (a) at $1100 \mathrm{~cm}^{-1}$ that could be attributed to the asymmetric stretching vibration of Fe-O-Fe or Al-O-Al bonds [25] and (b) at $1080-980 \mathrm{~cm}^{-1}$ that can be assigned to symmetrical stretching vibrations of $\mathrm{Si}-\mathrm{O}-\mathrm{Fe}$ and $\mathrm{Si}-\mathrm{O}-\mathrm{Al}$ bonds [41,42], respectively. Moreover, the existence of stretching and bending vibrations of the $\mathrm{Fe}-\mathrm{OH}-\mathrm{Fe}$ or $\mathrm{Al}-\mathrm{OH}-\mathrm{Al}$ bonds, may indicate the presence of the respective polymers, formed in the samples, which can be proved also by the two strong absorption peaks at $1098-1100$ and $831-833 \mathrm{~cm}^{-1}$ wavelengths (see also References [41,42]). It is obvious from Figure 1 that the mixing order had no effect on the relevant FTIR spectra, as rather similar peaks were detected. 


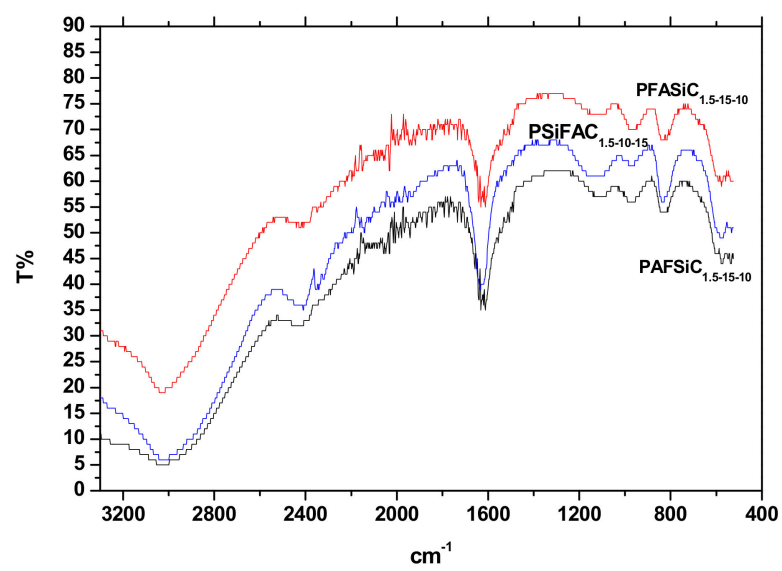

Figure 1. FTIR spectra of composite coagulants prepared with different mixing order of $\mathrm{Al} / \mathrm{Fe} / \mathrm{Si}$ components, i.e., $\mathrm{PSiFAC}_{1.5-10-15}, \mathrm{PAFSiC}_{1.5-15-10}$, and $\mathrm{PFASiC}_{1.5-15-10}$.

In Figure 2, the corresponding FTIR spectra comparing PSiFAC $1.5-10-15$ with PAPEFAC $1.5-10-15$ (which is the material containing the anionic polyelectrolyte in its structure, instead of poly-silicic acid) are presented. As it can be noticed, the latter material was found to present similar absorption

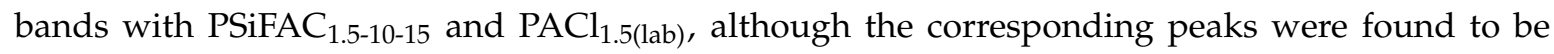
more intensive.

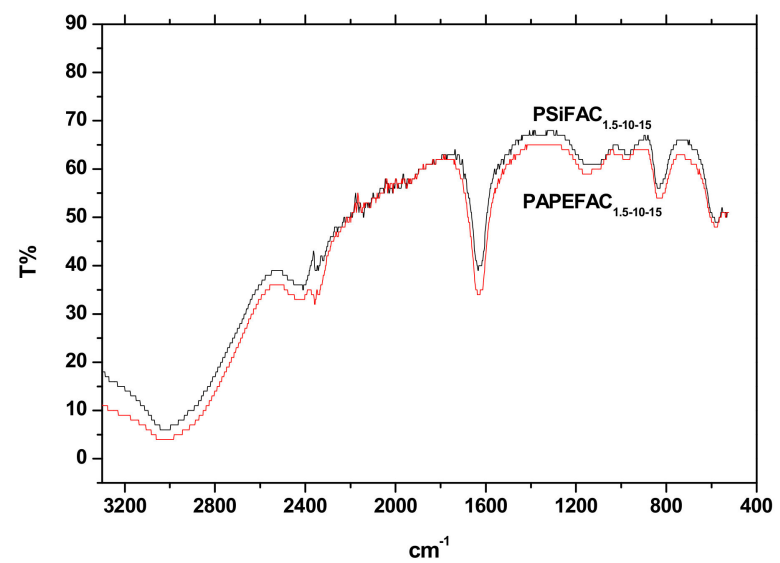

Figure 2. FTIR spectra comparing PSiFAC $1.5-10-15$ and PAPEFAC $1.5-10-15$ samples.

\subsubsection{Morphological Analysis}

The comparison of the surface of the solid residue, which remains after drying of coagulants' solutions, could give useful information about the structural changes that possibly take place due to the addition of polysilicates and/or iron on the surface of PACl. Additionally, the further elemental analysis with the application of SEM/EDS of these samples, focusing on specific areas on the surface of the solid residues, is expected to contribute significantly to the better understanding of the nature (composition) and structure of the new coagulants. It is for this reason that the SEM images are presented in this article, i.e., contributing to the SEM/EDS atomic analysis of the obtained cubic crystals. Figure 3a illustrates the SEM images of dried samples, regarding the different mixing order of $\mathrm{Al} / \mathrm{Fe} / \mathrm{Si}$ components, whereas, for comparison reasons, the corresponding SEM image for $\mathrm{PACl}_{1.5(\mathrm{lab})}$ at Figure $3 \mathrm{~d}$ is also presented. Several different morphologies were observed, the most predominant being a cubic-like morphology and a separate compact solid surface. Initially, these cubes were considered to be $\mathrm{NaCl}$ crystals, separated from the other constituents. 

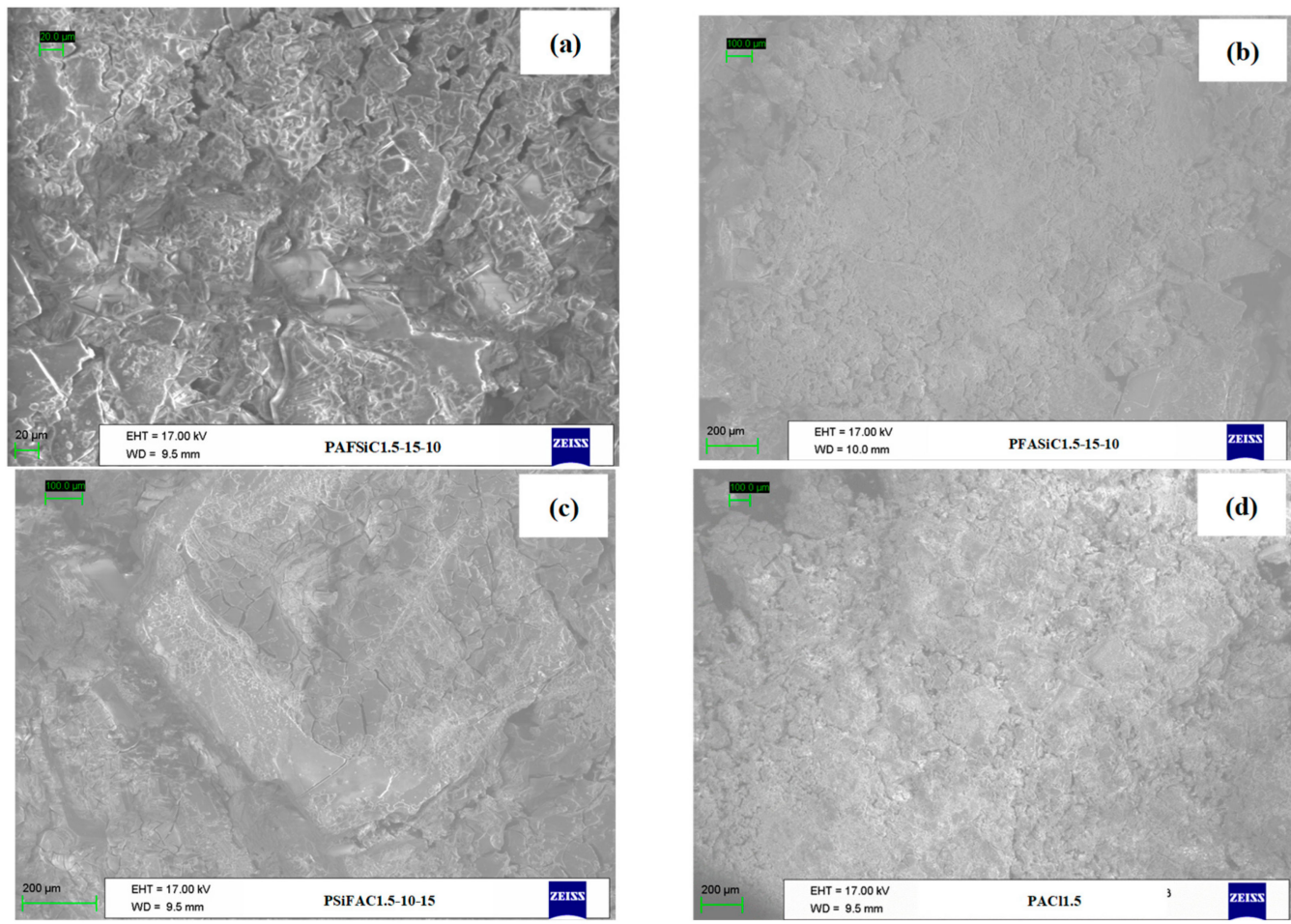

Figure 3. SEM images of composite coagulant samples obtained after drying in an oven under constant low temperature $\left(\sim 40^{\circ} \mathrm{C}\right)$. (a) PAFSiC $1.5-15-10$, (b) $\mathrm{PFASiC}_{1.5-15-10}$, (c) $\mathrm{PSiFAC}_{1.5-10-15}$, and (d) $\mathrm{PACl}_{1.5(\mathrm{lab})}$.

However, further atomic analysis with the application of SEM/EDS, as presented in Table 4, revealed that these cubes consist from the sum of elements $\mathrm{Na}, \mathrm{Al}, \mathrm{Si}, \mathrm{O}, \mathrm{Cl}$, and $\mathrm{Fe}$ (expressed as $\% \mathrm{w} / \mathrm{w}$ of the relative content). The low relative $\mathrm{Na}$ content and the significantly higher $\mathrm{Cl}$ content indicate that in addition to $\mathrm{NaCl}$, other chemical forms can also be involved in the formation of these cubes such as various $\mathrm{Al}$ forms and perhaps alumino-silicates. In the case of $\mathrm{PACl}_{1.5(\mathrm{lab})}$ (prepared with $[\mathrm{OH}] /[\mathrm{Al}]=1.5$ ratio), generally similar configurations were observed, i.e., cubic-shaped crystals and a distinct amorphous surface.

Table 4. The SEM/EDS atomic analysis of cubic crystals obtained from the respective dried composite coagulant samples.

\begin{tabular}{cccc}
\hline$\%(w / w)$ & PAFSiC $_{\mathbf{1 . 5}-\mathbf{1 5}-\mathbf{1 0}}$ & PFASiC $_{\mathbf{1 . 5 - 1 5 - 1 0}}$ & PSiFAC $_{\mathbf{1 . 5 - 1 0 - 1 5}}$ \\
\hline $\mathrm{Na}$ & 11.48 & 2.96 & 2.23 \\
\hline $\mathrm{O}$ & 35.46 & 44.66 & 43.89 \\
\hline $\mathrm{Cl}$ & 33.29 & 28.49 & 26.91 \\
\hline $\mathrm{Al}$ & 11.47 & 15.61 & 17.01 \\
\hline $\mathrm{Fe}$ & 4.07 & 4.73 & 5.78 \\
\hline $\mathrm{Si}$ & 0.03 & 0.67 & 1.36 \\
\hline
\end{tabular}

According to the obtained results, PSiFAC $1.5-10-15$ had the most compact form of all the materials examined in this case. It also had the highest content of $\mathrm{Al}, \mathrm{Fe}$, and $\mathrm{Si}$ and the lowest of $\mathrm{Na}$ compared to all other materials as defined by the application of chemical analysis with SEM/EDS (applied locally, i.e., in specific sites of the respective surfaces) which may indicate that the new coagulant PSiFAC $1.5-10-15$ is a stable material, even after drying at $40{ }^{\circ} \mathrm{C}$ without any particular loss or change of its components. The presence of aluminum in the branches observed in the relevant SEM image can be considered an indication of the interactions between the chemical forms of aluminum, iron, and silicates. 


\subsubsection{X-ray Diffraction Spectroscopy (XRD)}

From the XRD diagram of the PSiFAC $15-10-15$ sample containing $51 \% \mathrm{Al}_{\mathrm{b}}$ (after drying) and considered to be the relatively best product, three specific compounds were identified according to the respective database, i.e., sodium chloride $(\mathrm{NaCl})$, aluminum chloride hexahydrate $\left(\mathrm{AlCl}_{3} \cdot 6 \mathrm{H}_{2} \mathrm{O}\right)$, and a compound with 13 aluminum atoms (i.e., $\mathrm{Al}_{13} \mathrm{Cl}_{15}(\mathrm{OH})_{24} \cdot 37.5 \mathrm{H}_{2} \mathrm{O}$ ) as illustrated in Figure 4. The crystallinity of this sample was scarcely apparent when observing the nature of the respective peaks. The high-intensity peaks showed relatively narrow widths which indicate a high degree of crystallinity, whereas the other, lower intensity peaks appeared to be wider.

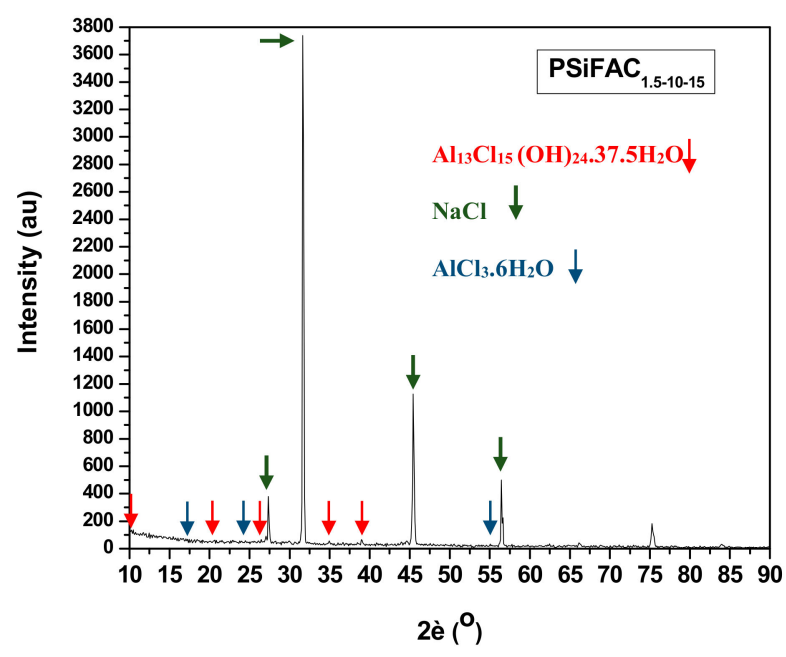

Figure 4. XRD diagram of the PSiFAC $15-10-15$ sample.

Particularly, $\mathrm{NaCl}$ is formed as a by-product during the reaction of neutralizing the aluminum solution by the addition of the alkaline solution. The XRD technique is particularly sensitive to crystalline $\mathrm{NaCl}$ formation due to the fact of its crystal size and structure which explains the high intensity peaks at $2 \theta$ angles $27^{\circ}, 32^{\circ}, 46^{\circ}$, and $57^{\circ}$. Aluminum chloride was also detected at very low concentrations as shown by the intensity of respective peaks. This particular coagulant, PSiFAC $15-10-15$, produced by a molecular ratio $[\mathrm{OH}] /[\mathrm{Al}]=1.5$, means that the neutralization of aluminum solution was not complete. Therefore, a certain amount of the original $\mathrm{AlCl}_{3}$ solution would not react as shown in the XRD diagram. Two of the three aforementioned compounds (i.e., $\mathrm{NaCl}$ and $\mathrm{AlCl}_{3}$ ) were also identified by other researchers in the pre-polymerized aluminum-based coagulants [25], whereas the compound with 13 aluminum atoms was previously identified by Tzoupanos et al. (2009) [34].

A specific characteristic of $\mathrm{Al}_{13}$ noticed during the XRD analysis was the appearance of relatively sharp peaks at low angles $\left(5-35^{\circ} 2 \theta\right)$ with the respective chemical formula identified as $\mathrm{Al}_{13} \mathrm{Cl}_{15}(\mathrm{OH})_{24} \cdot 37.5 \mathrm{H}_{2} \mathrm{O}$. This identification was carried out after several tests, noting that the sensitivity of detection by the XRD technique was significantly affected by the presence of formed $\mathrm{NaCl}$.

\subsubsection{Z-Potential and Size Measurements}

In Figure 4, the relevant comparison diagrams of the zeta-potential and particle size measurements of certain examined coagulants were presented; the values of initial $\mathrm{pH}$ samples, zeta-potential, particle sizes, and iso-electric points (IEPs) are displayed in Table 5. The applied coagulant dosage was the same (i.e., $10 \mathrm{mg} \mathrm{Al} / \mathrm{L}$ in deionized water) for each coagulant. Figure 4 shows also that an increase in $\mathrm{pH}$ values can cause a reduction of $z$-potential values of the samples but an increase in the respective particle size. This is most likely attributed to the fact that the $\mathrm{pH}$ difference can result in the decrease of the positive charge of the formed particles which tend to be neutralized at the respective IEPs. Consequently, the overall negative charge is prevailing at $\mathrm{pH}$ values higher than IEP, causing the (desirable) destabilization of colloidal system. 
Table 5. Initial $\mathrm{pH}$ (after coagulant addition), zeta-potential, sizes and iso-electric point (IEP) values for certain examined coagulants, tested at $10 \mathrm{mg} \mathrm{Al} / \mathrm{L}$ dosage in distilled water.

\begin{tabular}{ccccc}
\hline Coagulant & Initial $\mathbf{~ H H}$ & $\begin{array}{c}\text { Initial Zeta-Potential } \\
\mathbf{( m \mathbf { ~ } )}\end{array}$ & $\begin{array}{c}\text { Initial Size } \\
\mathbf{( n \mathbf { m } )}\end{array}$ & $\begin{array}{c}\text { Iso-Electric Point } \\
\text { (IEP) }\end{array}$ \\
\hline PSiFAC $_{15-10-15}$ & 4.87 & 50.5 & 189 & 9.10 \\
\hline PAPEFAC $_{1.5-10-15}$ & 2.52 & 39.2 & 245 & 9.56 \\
\hline PASiC $_{1.5-15}$ & 3.63 & 35.9 & 216 & 9.40 \\
\hline
\end{tabular}

The PSiFAC $1.5-10-15$ is the coagulant that presented the highest initial positive value of zeta-potential (i.e., $50.5 \mathrm{mV}$ ) [32], followed by PAPEFAC $1.5-10-15(39.2 \mathrm{mV})$, and by PASiC $1.5-15$ (similar $35.9 \mathrm{mV}$ ). The IEP values for these coagulants were 9.10, 9.56, and 9.40, respectively. Figure 5a shows that for all these coagulants, the IEP values were found to be greater than eight, which means that at lower $\mathrm{pH}$ values, an overall positive charge prevails, favoring the interaction of aluminum species with the (mainly) negatively charged components (e.g., phosphates) in wastewaters.
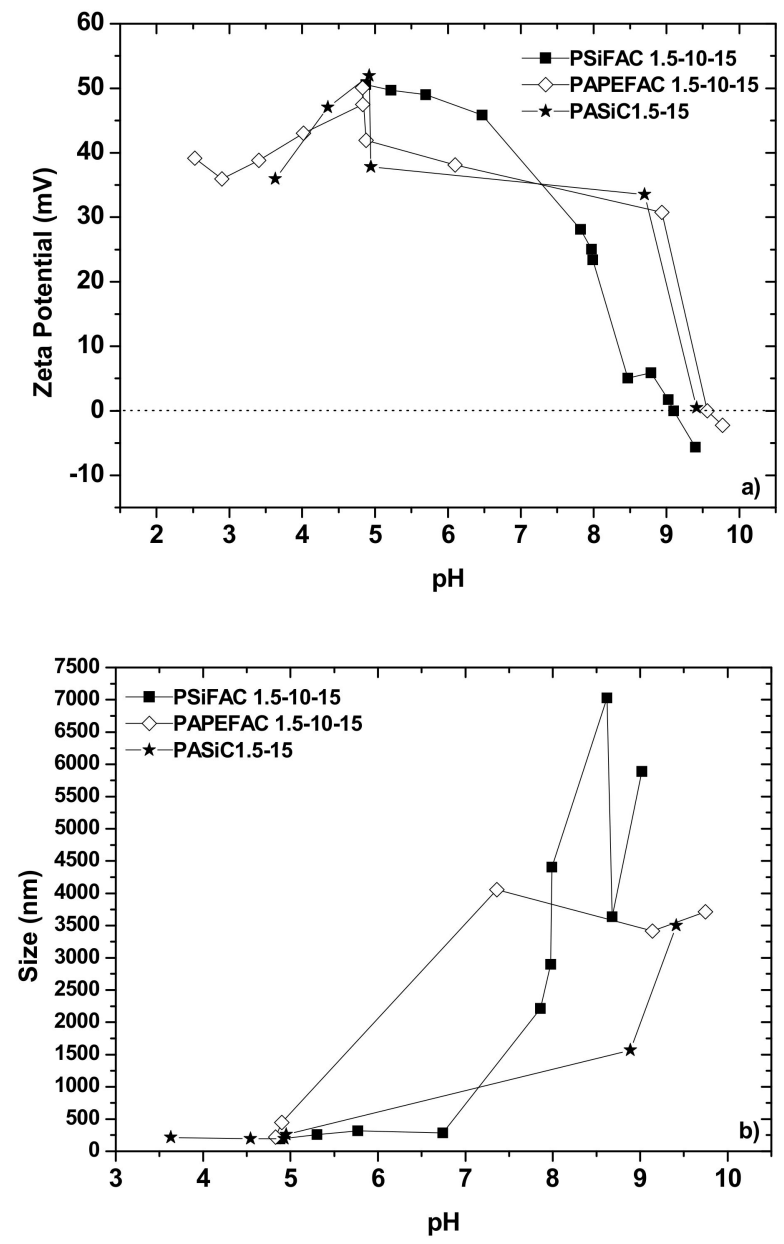

Figure 5. Comparison of (a) zeta-potential and (b) size measurements ( $\mathrm{nm}$ ) as a function of respective $\mathrm{pH}$ values for certain examined coagulants, i.e., $\mathrm{PSiFAC}_{15-10-15}, \mathrm{PAPEFAC}_{1.5-10-15}$, and PASiC $1.5-15$.

The initial particle size of PSiFAC $1.5-10-15$ [32] was approximately $189 \mathrm{~nm}$, while the relative size of PAPEFAC ${ }_{1.5-10-15}$ and PASiC ${ }_{1.5-15}$ products was higher, i.e., 245 and $216 \mathrm{~nm}$, respectively, and increased substantially as the $\mathrm{pH}$ value further rose. The results depict that all these chemical agents can be classified as nano-scale coagulants. Figure $5 \mathrm{~b}$ shows that the size of PSiFAC $1.5-10-15$ and PAPEFAC $1.5-10-15$ particles/flocs increased drastically at $\mathrm{pH}$ values around 7.0 which is most likely 
attributed to the formation of $\mathrm{Al}(\mathrm{OH})_{3}$ and $\mathrm{Fe}(\mathrm{OH})_{3}$ precipitates, in comparison with $\mathrm{PASiC}_{1.5-15}$, which does not contain $\mathrm{Fe}$, and its relevant size increased at (around) $\mathrm{pH} 9$.

\subsection{Coagulation Performance}

\subsubsection{Tannery Wastewater}

Initially, the poly-aluminum-ferric-silicate-chloride coagulants were compared in terms of turbidity removal (Figure S2) in order to obtain the optimum mixing order of the component's $\mathrm{Al} / \mathrm{Fe} / \mathrm{pSi}$. As it is shown, all these coagulants reduced the turbidity of the tannery wastewater sample for doses greater than $60 \mathrm{mg} \mathrm{Al} / \mathrm{L}$.

The most effective coagulant obtained, namely, PSiFAC $_{1.5-10-15}$ was further applied to tannery wastewater treatment, aiming to evaluate its efficiency for the treatment of a typical high-strength industrial wastewater. The results of coagulation experiments for the removal (\%) of turbidity (expressed as NTU units), COD, and phosphates are shown in Figure S3. As it can be observed, PSiFAC $_{1.5-10-15}$ significantly reduced turbidity, COD, and phosphates for doses above $30 \mathrm{mg} \mathrm{Al} / \mathrm{L}$.

The main goal of this study was to examine the effectiveness of the coagulation/flocculation $(\mathrm{C} / \mathrm{F})$ process using the new composite poly-aluminum-ferric-silicate-chloride coagulants. Then, in an attempt to optimize the treatment, a flocculant aid, such as the typical anionic polyelectrolyte-APE, was also used to improve the treatment of this wastewater sample. The new material synthesized in this study, PAPEFAC $1.5-10-15$, which contains the anionic polyelectrolyte in its structure and is a combination of coagulant and polyelectrolyte in a single reagent, by replacing the inorganic poly-silicate additive with the organic polyelectrolyte, was also studied for comparative reasons.

In Figure 6, the results of the application of these materials to the removal of turbidity, COD, and phosphates, applying a coagulant dose of $30 \mathrm{mg} \mathrm{Al} / \mathrm{L}$, are shown. However, from the presented results, the addition of a common anionic polyelectrolyte, either as a separate flocculation aid/enhancer (i.e., $\mathrm{PSiFAC}_{1.5-10-15}+\mathrm{APE}$ ) or as an additive in the respective product structure (i.e., as PAPEFAC $1.5-10-15$ ) did not produce any specific improvement on PSiFAC $1.5-10-15$ performance, except the additional benefit from the use of a single material which avoids the use of special equipment to handle separately the polyelectrolyte (e.g., weighting, dissolution, pumping, etc.).

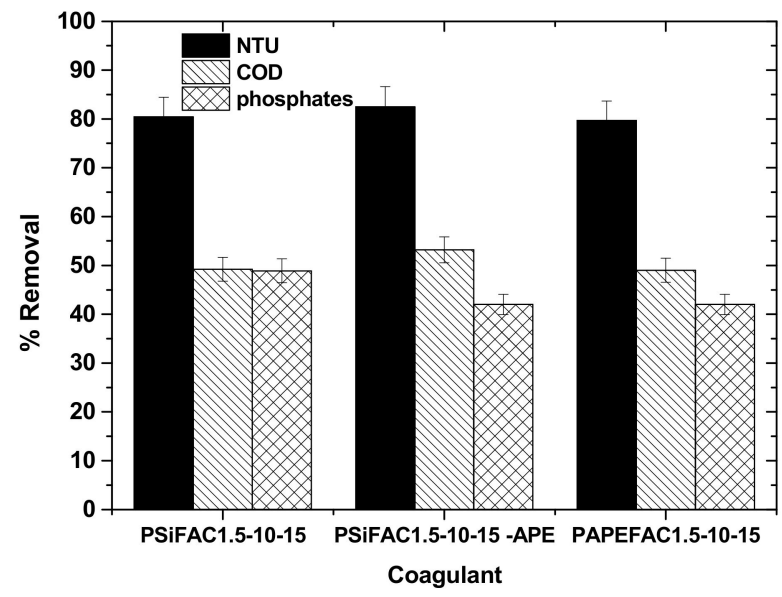

Figure 6. Removal (\%) of turbidity, COD, and phosphates with the application of PSiFAC $1.5-10-15$, PAPEFAC $_{1.5-10-15}$, and the addition of anionic polyelectrolyte (APE) as a flocculant aid, during tannery wastewater treatment with a coagulant dose $30 \mathrm{mg} \mathrm{Al} / \mathrm{L}$. The respective initial values were $668 \mathrm{NTU}$, COD $6800 \mathrm{mg} / \mathrm{L}$, phosphates $1.76 \mathrm{mg} / \mathrm{L}$, and $\mathrm{pH} 7.8$.

The results of this study present certain advantages over the relevant literature data, where substantially higher dosages are usually required, e.g., $800 \mathrm{mg} / \mathrm{L}$ [43] of aluminum sulfate for the treatment of tannery wastewater samples, providing 30\%-37\% removal of total COD, and more 
recently [44], when using (again) aluminum sulfate, the maximum removal $(60 \%)$ was observed for the dose $350 \mathrm{mg} / \mathrm{L}$; also, for the case of PACl, when using an initial concentration of $600 \mathrm{mg} / \mathrm{L}$, turbidity and COD removals of $99.3 \%$ and $83.3 \%$ were found, respectively [45]. Finally, there are no data in the scientific literature for the use of composite pre-polymerized coagulants regarding the treatment of high-strength wastewaters.

\subsubsection{Yeast Production Wastewater}

The optimum coagulant obtained during the treatment of tannery wastewater sample as well as during previous relevant studies [30,32] (i.e., the PSiFAC $1.5-10-15$ ) was also applied to treat the yeast production wastewater, examining two different samples (i.e., a yeast manufacturing wastewater, subjected to preliminary anaerobic treatment, and another sample which was supplementary subjected to aerobic treatment (besides the previous anaerobic)) aiming to evaluate its efficiency for the treatment of a typical high-strength difficult to be treated industrial wastewater. The results of coagulation experiments, regarding the removal (\%) of turbidity (NTU), COD, and phosphates, are shown in Figure 7 for the sample subjected to preliminary anaerobic/aerobic treatment. As it can be observed from these results, PSiFAC $_{1.5-10-15}$ was found to enhance the removal rate, particularly of turbidity and orthophosphates, at doses greater than $50 \mathrm{mg} \mathrm{Al} / \mathrm{L}$.

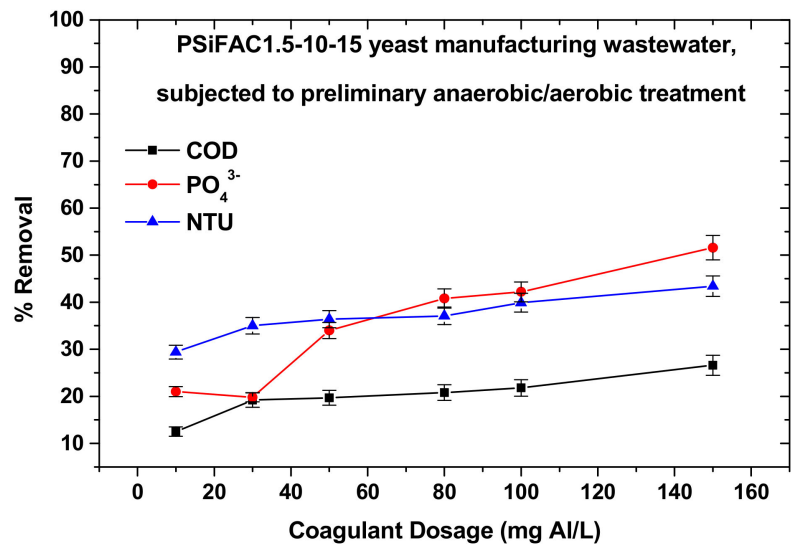

Figure 7. Removal (\%) of turbidity, COD, and phosphates with the application of PSiFAC $1.5-10-15$ in yeast production wastewater samples subjected to preliminary anaerobic/aerobic treatment. The respective initial values of this sample were 143 NTU, COD $4590 \mathrm{mg} / \mathrm{L}$, phosphate $2.4 \mathrm{mg} / \mathrm{L}$, and pH 7.9.

Attempting to optimize further the treatment of this wastewater (improve efficiency) and for comparison purposes, an anionic polyelectrolyte-APE was separately applied as flocculant aid together with the same coagulant, as well as: (a) the PAPEFAC $1.5-10-15$ coagulant, which contained the anionic polyelectrolyte in its structure, (b) the PASiC $1.5-15$, which did not contain iron in its structure, and (c) the

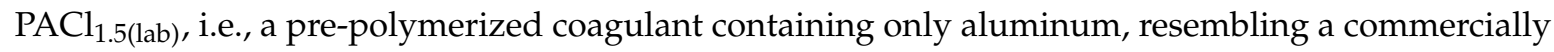
available relevant product. In Figure S4, the results of the application of these materials for the removal of turbidity, COD, and phosphates with a coagulant dose of $80 \mathrm{mg} \mathrm{Al} / \mathrm{L}$ are shown, regarding the treatment of both yeast production wastewater samples.

As depicted from the results of Figure S4, the addition of polyelectrolyte as a flocculant enhancer/aid was found to improve the efficiency of all applied coagulants, especially in the case of PASiC $1.5-15$. However, it is quite remarkable the fact that the addition of the PAPEFAC $1.5-10-15$ coagulant, i.e., that incorporating also the polyelectrolyte into its structure, exhibited satisfactory removal rates, which suggests that it could also be used as a single reagent during wastewater treatment, i.e., without the need for special additional equipment for the handling the polyelectrolyte, thereby reducing the overall treatment costs. 


\subsubsection{Comparison of Industrial Wastewater Treatment Results}

The comparative diagrams of industrial wastewater treatment using $80 \mathrm{mg} \mathrm{Al} / \mathrm{L}$ of the best PSiFAC $1.5-10-15$ coagulant product as well as of the PSiFAC ${ }_{1.5-10-15}$ coagulant plus the separate APE addition and of the composite PAPEFAC $1.5-10-15$ are shown in Figure 8, regarding the removal (\%) of (a) turbidity, (b) COD, and (c) phosphates. The results showed that the addition of $80 \mathrm{mg} \mathrm{Al} / \mathrm{L}$ of PSiFAC $_{1.5-10-15}$ to tannery wastewater sample, either with or without the supplement of a common anionic polyelectrolyte, acting as flocculant aid or incorporated in its structure, resulted in substantial reductions of COD (67\%), turbidity $(96 \%)$, and phosphates $(62 \%)$.
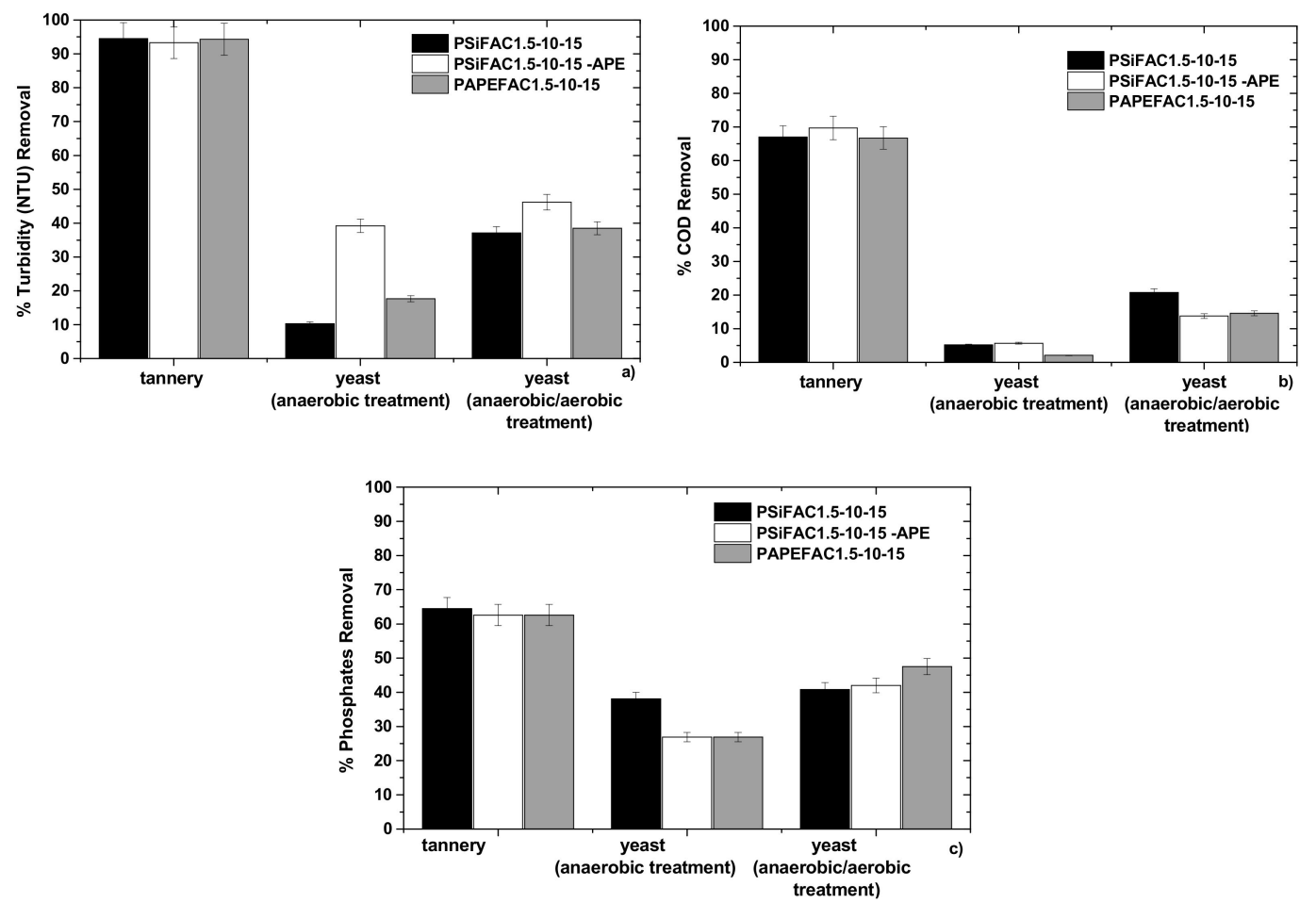

Figure 8. Comparison of high-strength industrial wastewater treatment, i.e., tannery sample and yeast production samples (following anaerobic pre-treatment or anaerobic/aerobic pre-treatment) by applying $80 \mathrm{mg} \mathrm{Al} / \mathrm{L}$ of PSiFAC $1.5-10-15$, PSiFAC $_{1.5-10-15}$ with APE addition (separately), and PAPEFAC $1.5-10-15$ regarding the removal (\%) of (a) turbidity, (b) COD, and (c) phosphates.

In addition, by applying these coagulants to the yeast production wastewater samples, the same dose resulted in a relatively lower reduction of COD (56\%), turbidity (40\%), and phosphates $(43 \%)$ for the anaerobically pre-treated wastewater samples, whereas an even smaller reduction (i.e., COD $22 \%$, turbidity $14 \%$, and phosphate $38 \%$ ), was noticed for the anaerobically and aerobically pre-treated wastewater samples. However, it is evident (Figure 8) that higher rates of turbidity removal, approaching $45 \%-50 \%$, were obtained when the coagulant and the polyelectrolyte were combined in a single reagent (PAPEFAC $1.5-10-15)$, although regarding the reduction of COD, the use of PSiFAC $1.5-10-15$ without the addition of the polyelectrolyte enhancer/flocculant aid showed better results.

\subsubsection{Residual Aluminum Concentration}

The residual aluminum concentration is considered as particularly important parameter from the perspective of human health and should be carefully considered when an aluminum coagulant is applied, especially for drinking water treatment. According to Figure 9, it can be seen that the residual Al concentration remained well under the respective legislation limit of $200 \mu \mathrm{g} \mathrm{Al} / \mathrm{L}$, according to the EU Directive 98/83/EC, for the examined coagulants, and for all the examined wastewater samples. 


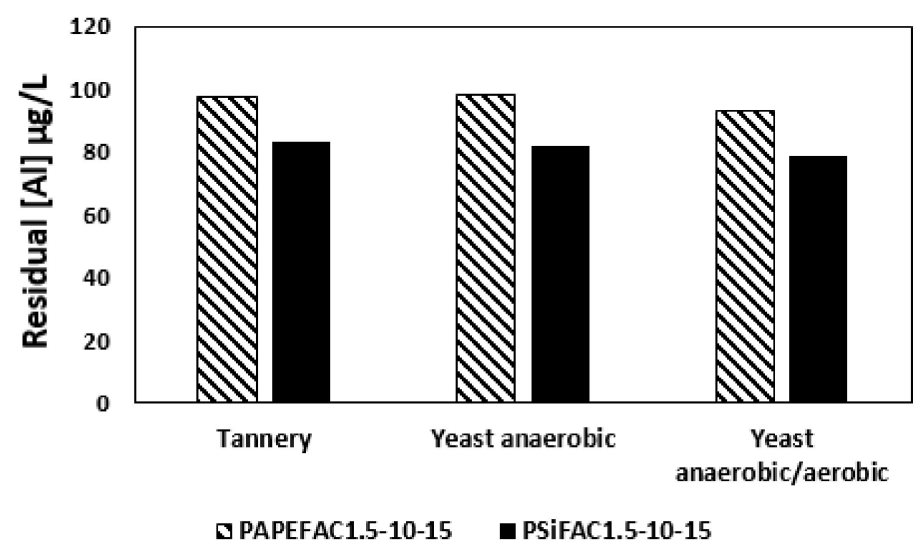

Figure 9. Residual aluminum concentration for the same coagulants' dose (80 $\mathrm{mg} \mathrm{Al} / \mathrm{L})$, regarding PSiFAC $_{1.5-10-15}$ and PAPEFAC $1.5-10-15$ in all examined wastewater samples.

\section{Conclusions}

In this study, different composite poly-aluminum-ferric-silicate-chloride (PSiFAC) coagulants were prepared in the laboratory, and their efficiency was examined for the treatment of high-strength industrial wastewaters, such as those originating in tanneries, or in yeast-production (fermentation) plants. The contribution of polyelectrolyte during the coagulation/flocculation process was additionally studied by two different types of process application, i.e., either the polyelectrolyte was separately added in the sample as a supplementary flocculation aid or the coagulant and the polyelectrolyte were combined in one single reagent (PAPEFAC) in order to increase further the flocculation efficiency.

The properties and characteristics of commonly applied poly-aluminum-chloride $(\mathrm{PACl})$ were affected by the introduction of poly-silicates or polyelectrolyte, simultaneously with ferric cations in its structure. According to the presented results, the new composite coagulants, i.e., PSiFAC $_{1.5-10-15}$ and PAPEFAC ${ }_{1.5-10-15}$ showed the relatively higher $\mathrm{Al}_{13}$ content, i.e., $51 \%$ and $43 \%$. Consequently, the FTIR and SEM analyses of these composite coagulants indicated a similarity in their structure and morphology which were not affected by the different preparation methods (addition order of the chemicals) of the samples. Furthermore, polymerization was noticed for both coagulants by observing the existence of intensive peaks in the FTIR spectra which can be attributed to the stretching and bending vibration of $\mathrm{Fe}-\mathrm{OH}-\mathrm{Fe}$ and $\mathrm{Al}-\mathrm{OH}-\mathrm{Al}$ bonds, respectively. The SEM micrographs showed the resulting amorphous structures on the surface of all prepared composite coagulants, pointing at the same time to the formation of $\mathrm{NaCl}$ as clinging block-shaped crystals.

The coagulants proved to be quite effective, depending upon their specific properties; the addition of $80 \mathrm{mg} \mathrm{Al} / \mathrm{L}$ in yeast production wastewater samples resulted in a sufficient reduction of COD $(56 \%)$, turbidity $(40 \%)$, and phosphates $(43 \%)$ for the anaerobically pre-treated wastewater sample; an extra reduction of COD $(22 \%)$, turbidity $(14 \%)$, and phosphates $(38 \%)$ was noticed for the pre-treated anaerobically/aerobically wastewater treatment samples, respectively. Compared to these results, higher removal rates were obtained for the treatment of tannery wastewater (i.e., COD $67 \%$, turbidity $96 \%$, phosphates $62 \%$ ).

Conclusively, it was found that the PSiFAC 1.5:10:15 coagulant, either with or without the addition of a common flocculant aid (polyelectrolyte), can provide better effectiveness of the C/F process, especially regarding COD removal. The residual aluminum concentration in the treated wastewaters was found to be below the maximum concentration limit of $\mathrm{Al}$ even for drinking water $(200 \mu \mathrm{g} / \mathrm{L})$. Certain additional cost benefits may arise by the utilization of this material in specific wastewater treatment cases, including the possible avoidance of equipment for handling the organic polyelectrolyte reagent (e.g., dissolution, pumping). In this way, the overall treatment procedure is simplified, and the overall cost-effectiveness can be improved. 
Supplementary Materials: The following are available online at http:/www.mdpi.com/2073-4441/12/5/1258/s1, Figure S1: FT-IR spectra of PACl $1.5(\mathrm{lab})$, for comparison reasons; Figure S2: Determination of optimum mixing order of the chemical components, for the coagulants PAFSiC $1.5-15-10$, PFASiC $_{1.5-15-10} \mathrm{~K}_{\mathrm{L}} \mathrm{PSiFAC}_{1.5-10-15}$, regarding the removal of turbidity, in tannery wastewater samples. The respective initial values of this wastewater were $668 \mathrm{NTU}$ and pH 7.8; Figure S3: Removal (\%) of turbidity, COD and phosphates, by applying the PSiFAC $1.5-10-15$ coagulant during tannery wastewater treatment. The initial values of these parameters were $668 \mathrm{NTU}, \mathrm{COD} 6800 \mathrm{mg} / \mathrm{L}$, phosphate $1.76 \mathrm{mg} / \mathrm{L}$ and $\mathrm{pH}$ 7.8; Figure S4: Removal (\%) of turbidity, COD and phosphates, with the application of PSiFAC $1.5-10-15$, PAPEFAC $_{1.5-10-15}, \mathrm{PASiC}_{1.5-15}, \mathrm{PACl}_{1.5}$ (lab) and addition of anionic polyelectrolyte (APE) as a flocculant aid, in yeast production wastewater treatment with a coagulant dose of $80 \mathrm{mg} \mathrm{Al} / \mathrm{L}$, (a) subjected to preliminary anaerobic treatment; (b) the latter sample additionally subjected to aerobic treatment,. The respective initial values of wastewater samples were (a) $418 \mathrm{NTU}$, COD $11455 \mathrm{mg} / \mathrm{L}$, phosphates $3.49 \mathrm{mg} / \mathrm{L}, \mathrm{pH} 7.9$ and (b) $143 \mathrm{NTU}, \mathrm{COD} 4590 \mathrm{mg} / \mathrm{L}$, phosphates $2.4 \mathrm{mg} / \mathrm{L}$ and $\mathrm{pH}$ 8.6, for the two wastewater samples.

Author Contributions: Data curation, A.K.T.; Investigation, A.K.T.; Methodology, A.K.T.; Writing-Original draft, A.K.T.; Validation, A.I.Z.; Visualization, A.K.T. and A.I.Z.; Writing-Review and editing, A.K.T. and A.I.Z.; Supervision, A.I.Z. All authors have read and agreed to the published version of the manuscript.

Funding: This research was funded by the European Union and the Greek State Program EPAN-II (OPC-II)/ESPA (NSRF): SYNERGASIA II, Project (FOUL-MEM), grant number 11SYN-8-1084, entitled "New processes for fouling control in membrane bioreactors".

Acknowledgments: A part of characterization of the coagulants was executed under the framework of the IKYDA 2016 project ACR-Tech, which involved cooperation between the Aristotle University of Thessaloniki and the Technical University of Hamburg.

Conflicts of Interest: The authors declare that they have no conflict of interest.

\section{References}

1. Kelley, D.; Handley, R. Compositions and Methods for Wastewater Treatment. U.S. Patent 7, 931,822, 26 April 2011.

2. Raptopoulou, C.; Kalaitzidou, K.; Tolkou, A.; Palasantza, P.A.; Mitrakas, M.; Zouboulis, A. Phosphate Removal from Effluent of Secondary Wastewater Treatment: Characterization of Recovered Precipitates and Potential Re-use as Fertilizer. Waste Biomass Valorization 2016, 7, 851-860. [CrossRef]

3. Kalaitzidou, K.; Mitrakas, M.; Raptopoulou, C.; Tolkou, A.; Palasantza, P.A.; Zouboulis, A. Pilot-Scale Phosphate Recovery from Secondary Wastewater Effluents. Environ. Proc. 2016, 3, 5-22. [CrossRef]

4. Tolkou, A.; Zouboulis, A. Review of Recent Patents on Coagulation/Flocculation (C/F) Process: Methods and Applications with Emphasis on Phosphates Removal. Recent Pat. Mater. Sci. 2014, 7, 151-163. [CrossRef]

5. Kim, H.C.; Dempsey, B.A. Effects of wastewater effluent organic materials on fouling in ultrafiltration. Water Res. 2008, 42, 3379-3384. [CrossRef]

6. Lee, J.; Lee, J.W.; Kim, Y.M.; Park, C.; Park, K.Y. Performance and Fouling in Pre-Denitrification Membrane Bioreactors Treating High-Strength Wastewater from Food Waste Disposers. Water 2017, 9, 512. [CrossRef]

7. Mutamim, N.S.A.; Noor, Z.Z.; Hassan, M.A.A.; Olsson, G. Application of membrane bioreactor technology in treating high strength industrial wastewater: A performance review. Desalination 2012, 305, 1-11. [CrossRef]

8. Swain, K.; Abbassi, B.; Kinsley, C. Combined Electrocoagulation and Chemical Coagulation in Treating Brewery Wastewater. Water 2020, 12, 726. [CrossRef]

9. Akansha, J.; Nidheesh, P.V.; Gopinath, A.; Anupama, K.V.; Suresh Kumar, M. Treatment of dairy industry wastewater by combined aerated electrocoagulation and phytoremediation process. Chemosphere 2020, 253, 126652. [CrossRef]

10. Saxena, G.; Purchase, D.; Bharagava, R.N. Environmental Hazards and Toxicity Profile of Organic and Inorganic Pollutants of Tannery Wastewater and Bioremediation Approaches. In Bioremediation of Industrial Waste for Environmental Safety; Saxena, G., Bharagava, R., Eds.; Springer: Singapore, 2020.

11. Tolkou, A.; Zouboulis, A. Effect of climate change in WWTPs with a focus on MBR infrastructure. Desalin. Water Treat. 2016, 57, 2344-2354. [CrossRef]

12. Eckenfelder, W.W. (Ed.) Industrial Water Pollution Control; McGraw-Hill Inc.: New York, NY, USA, $1999 ;$ p. 33.

13. Tchobanoglous, G.; Burton, F.L.; Stensel, H.D. Metcalf E Eddy Wastewater Engineering: Treatment and Reuse; McGraw-Hill Inc.: New York, NY, USA, 2003.

14. Chowdhurya, M.; Deb, A.K.; Biswas, T.K.; Bin Azam, F.A.; Hossain, D. Removal of Toxicants from Leather Industrial Wastewater Using Sawdust Filter Media and Ferric Oxide Coagulant. Orient. J. Chem. 2019, 35, 597-604. [CrossRef] 
15. Chung, C.Y.; Selvarajoo, A.; Sethu, V.; Koyande, A.K.; Arputhan, A.; Lim, Z.C. Treatment of palm oil mill effluent (POME) by coagulation flocculation process using peanut-okra and wheat germ-okra. Clean Technol. Environ. Policy 2018, 20, 1951-1970. [CrossRef]

16. Jagaba, A.H.; Kutty, S.R.M.; Hayder, G.; Latiff, A.A.A.; Aziz, N.A.A.; Umaru, I.; Ghaleb, A.A.S.; Abubakar, S.; Lawal, I.M.; Nasara, M.A. Sustainable use of natural and chemical coagulants for contaminants removal from palm oil mill effluent: A comparative analysis. Ain Shams Eng. J. 2020. In Press, Corrected Proof. [CrossRef]

17. Aleem, M.; Cao, J.; Li, C.; Rashid, H.; Wu, Y.; Nawaz, M.I.; Abbas, M.; Akram, M.W. Coagulation- and Adsorption-Based Environmental Impact Assessment and Textile Effluent Treatment. Water Air Soil Pollut. 2020, 231, 45. [CrossRef]

18. Manhokwe, S.; Shoko, S.; Zvidzai, C. Optimization of biological wastewater treatment for yeast processing effluent using cultured bacteria: Application of response surface methodology. Afr. J. Microbiol. Res. 2019, 13, 430-437. [CrossRef]

19. Lee, C.S.; Robinson, J.; Chong, M.F. A review on application of flocculants in wastewater treatment. Process Saf. Environ. 2014, 92, 489-508. [CrossRef]

20. Sinha, S.; Yoon, Y.; Amy, G.; Yoon, J. Determining the effectiveness of conventional and alternative coagulants through effective characterization schemes. Chemosphere 2004, 57, 1115-1122. [CrossRef] [PubMed]

21. Crittenden, J.C.; Truddel, R.R.; Hand, D.W.; Howe, K.J.; Tchobanoglous, G. Coagulation, Mixing and Flocculation. In Water Treatment: Principles and Design, 2nd ed.; John Wiley \& Sons: New Jersey, NJ, USA, 2005; pp. 664-691.

22. Gao, B.; Hahn, H.; Hoffmann, E. Evaluation of aluminium-silicate polymer composite as a coagulant for water treatment. Water Res. 2002, 36, 573-3581. [CrossRef]

23. Zouboulis, A.I.; Tzoupanos, N.D. Polyaluminium silicate chloride-A systematic study for the preparation and application of an efficient coagulant for water or wastewater treatment. J. Hazard. Mater. 2009, 162, 1379-1389. [CrossRef]

24. Zouboulis, A.I.; Moussas, P.A. Polyferric silicate sulphate (PFSiS): Preparation, characterization and coagulation behavior. Desalination 2008, 224, 307-316. [CrossRef]

25. Gao, B.Y.; Liu, L.L.; Zhou, W.Z.; Yue, Q.Y.; Li, Q. Study on the hydrolysis polymerization process of aluminum in polyaluminum silicate chloride (PASC) flocculant. Acta Sci. Circumstantiae 2005, 11, 1464-1469.

26. Niu, X.; Li, X.; Zhao, J.; Ren, Y.; Yang, Y. Preparation and coagulation efficiency of polyaluminum ferric silicate chloride composite coagulant from wastewater of high-purity graphite production. J. Environ. Sci. 2011, 23, 1122-1128. [CrossRef]

27. Li, R.; He, C.; He, Y. Preparation and characterization of poly-silicic-cation coagulants by synchronous-polymerization and co-polymerization. Chem. Eng. J. 2013, 223, 869-874. [CrossRef]

28. Sun, T.; Sun, C.H.; Zhu, G.L.; Miao, X.J.; Wu, C.C.; Lv, S.B.; Li, W.J. Preparation and coagulation performance of poly-ferric-aluminum-silicate-sulfate from fly ash. Desalination 2011, 268, 270-275. [CrossRef]

29. Tolkou, A.; Zouboulis, A. Synthesis and characterization of a novel composite pre-polymerized coagulant for water and wastewater treatment. Int. J. Environ. Eng. 2015, 2, 50-54.

30. Tolkou, A.K.; Zouboulis, A.I. Synthesis and coagulation performance of composite poly-aluminum-ferric-silicate-chloride coagulants in water and wastewater. Desalin. Water Treat. 2015, 53, 3309-3318. [CrossRef]

31. Katsoyiannis, I.; Tzollas, N.; Tolkou, A.; Mitrakas, M.; Ernst, M.; Zouboulis, A. Use of novel composite coagulants for arsenic removal from waters-Experimental insight for the application of polyferric sulfate (PFS). Sustainability 2017, 9, 590. [CrossRef]

32. Tolkou, A.; Mitrakas, M.; Katsoyiannis, I.; Ernst, E.; Zouboulis, A. Fluoride removal from water by composite $\mathrm{Al} / \mathrm{Fe} / \mathrm{Si} / \mathrm{Mg}$ pre-polymerized coagulants: Characterization and application. Chemosphere 2019, 231, 528-537. [CrossRef]

33. Gkotsis, P.K.; Mitrakas, M.; Tolkou, A.K.; Zouboulis, A.I. Batch and continuous dosing of conventional and composite coagulation agents for fouling control in a pilot-scale MBR. Chem. Eng. J. 2017, 311, 255-264. [CrossRef]

34. Tzoupanos, N.D.; Zouboulis, A.I.; Tsoleridis, C.A. A systematic study for the characterization of a novel coagulant (polyaluminium silicate chloride). Colloids Surf. A Physicochem. Eng. Asp. 2009, 342, 30-39. [CrossRef]

35. Bolto, B.A. Soluble polymers in water treatment. Prog. Polym. Sci. 1995, 20, 987-1041. [CrossRef] 
36. Mortimer, D.A. Synthetic polyelectrolytes: A review. Polym. Int. 1991, 25, 29-41. [CrossRef]

37. Clesceri, L.; Greenberg, A.; Trussell, R. Standard Methods for the Examination of Water and Wastewater, 17th ed.; APHA-AWWA-WEF: Washington, DC, USA, 1989.

38. Duan, J.; Gregory, J. The influence of silicic acid on aluminium hydroxide precipitation and flocculation by aluminium salts. J. Inorg. Biochem. 1998, 69, 193-201. [CrossRef]

39. Yan, M.; Wang, D.; Yu, J.; Ni, J.; Edwards, M.; Qu, J. Enhanced coagulation with polyaluminum chlorides: Role of pH/Alkalinity and speciation. Chemosphere 2008, 71, 1665-1673. [CrossRef] [PubMed]

40. Farmer, V.C.; Fraser, A.R.; Tait, J.M. Characterization of the chemical structures of natural and synthetic aluminosilicate gels and sols by infrared spectroscopy. Geochim. Cosmochim. Acta 1979, 43, 1417-1420. [CrossRef]

41. Moussas, P.A.; Zouboulis, A.I. Synthesis, Characterization and coagulation behavior of a composite coagulation reagent by the combination of Polyferric Sulphate (PFS) and cationic polyelectrolyte. Sep. Purif. Technol. 2012, 96, 263-273. [CrossRef]

42. Zhou, F.S.; Wang, S.H.; Su, J.Z.; Sun, H.; Zhu, P.; Ding, J.; Xu, Y.Z.; Wu, J.G. The infrared spectra and characteristics of PMC-A multicore inorganic polymer flocculant. Fine Chem. 2003, 10, 615-618.

43. Song, Z.; Williams, C.J.; Edyvean, R.G.J. Treatment of tannery wastewater by chemical coagulation. Desalination 2004, 164, 249-259. [CrossRef]

44. Arukula, D.; Prem, P.; Tanwi, P.; Hariraj, S.; Vijay, L.M.; Brijesh, K.M. Treatment of tannery wastewater using aluminum formate: Influence of the formate over sulphate-based coagulant. Glob. NEST J. 2018, 20, 458-464.

45. Sriwiriyarat, T.; Wongvian, R.; Kuhakaew, S. Selection of Coagulant with Consideration of Sludge Characteristics for Treatment of Industrial Wastewater Containing High Strength Mixed Surfactants. Chiang Mai J. Sci. 2017, 44, 1654-1668.

(C) 2020 by the authors. Licensee MDPI, Basel, Switzerland. This article is an open access article distributed under the terms and conditions of the Creative Commons Attribution (CC BY) license (http://creativecommons.org/licenses/by/4.0/). 